\title{
LIGA DE FUTEBOL JOSÉ DO PATROCÍNIO (1919-1936): UM SÍMBOLO DE RESISTÊNCIA AO PRECONCEITO RACIAL NO FUTEBOL PELOTENSE
}

CHRISTIAN FERREIRA MACKEDANZ

Doutorando em Educação Física na Universidade Federal de Pelotas (UFPel). Mestre em História pela mesma instituição. E-mail: christianfmackedanz@gmail.com ORCID: https://orcid.org/0000-0002-7024-812X.

DANIEL VIDINHA DA SILVA

Doutorando em Educação Física na Universidade Federal de Pelotas (UFPel). Mestre em Educação Física pela mesma instituição. E-mail: daniel.ef@hotmail.com.br. ORCID: https://orcid.org/0000-0001-7553-4603.

LUIZ CARLOS RIGO

Doutor em Educação pela Universidade Estadual de Campinas (UNICAMP). Professor titular com atuação na graduação e na pós-graduação da Escola Superior de Educação Física da Universidade Federal de Pelotas (UFPel). E-mail: rigoperini@gmail.com. ORCID: https://orcid.org/0000-0001-9586-0182.

RESUMO: Este estudo teve como objetivo descrever a emergência e a consolidação da Liga de Futebol José do Patrocínio, bem como problematizar o papel que essa liga desempenhou junto à comunidade negra pelotense no período pós-abolição. $O$ estudo caracteriza-se como uma pesquisa histórica, cujo corpus empírico constituise de jornais diários e semanais que circulavam na cidade na época da existência da Liga (1919-1936). Concluiu-se que a Liga serviu como uma alternativa à Liga Pelotense de Futebol que, na época, pautava-se por parâmetros elitistas e racistas. Desse modo, a Liga de Futebol José do Patrocínio foi um lócus de inclusão de futebolistas operários e afrodescendentes e representou um símbolo de resistência ao preconceito racial na cidade de Pelotas.

PALAVRAS-CHAVE: Futebol. Racismo. Pelotas. 


\title{
JOSÉ DO PATROCÍNIO FOOTBALL LEAGUE (1919-1936): A SYMBOL OF RESISTANCE TO RACIAL PREJUDICE IN PELOTAS FOOTBALL
}

\begin{abstract}
This study aimed to describe the emergence and consolidation of José do Patrocínio Football League, as well as to contest the League's role post-abolition period for the black Pelotas community. The study is a historical research, and the empirical corpus consisted of the analysis of city's daily and weekly newspapers during the League's existence (1919-1936). It was concluded that the League served as an alternative to the Pelotense Football League, which, at that time, was characterized by elitist and racist parameters. Therefore, José do Patrocínio Football League was a locus for including workers and Afro-descendant footballers and represented a symbol of resistance to racial prejudice in Pelotas city.
\end{abstract}

KEYWORDS: Football. Racism. Pelotas.

Recebido em 14/07/2020

Aprovado em: 07/01/2021

DOI: http://dx.doi.org/10.23925/2176-2767.2021v70p235-260 


\section{INTRODUÇÃO}

Quando comparado a outros países que também utilizaram a exploração do trabalho escravo africano, o racismo brasileiro constituiu-se a partir de certas singularidades. Segundo DaMatta (1981; 1990), nos casos norte-americano e sul-africano os brancos só conseguiram perpetuar a sua dominação sobre os negros através da criação de leis segregacionistas, pois tratava-se de sociedades bem mais competitivas e menos desiguais. A sociedade brasileira, ao contrário, era mais desigual e hierarquizada. Desse modo, após a abolição não foi necessária a realização de uma segregação amparada por leis, visto que os negros já estavam numa condição de subalternidade a partir da própria estrutura social. "Racismo à brasileira" é um dos termos utilizados para se referir a essa especificidade do preconceito racial brasileiro. Enquanto nos EUA vigorou a lógica de "iguais, mas separados", aqui, no Brasil, as lógicas utilizadas foram de "diferentes, mas juntos" (Idem, 1997, p. 18) e de "um lugar para cada coisa, cada coisa em seu lugar" (Idem, 1981, p. 83).

Assim, o racismo brasileiro se desenvolveu com uma refinada etiqueta de distanciamento social e uma diferenciação aguda de possibilidades econômicas, baseadas em diferenças fenotípicas. Outra particularidade brasileira fundamenta-se na concepção de que a "cor" é afetada pela estrutura econômica e de classe. Portanto, no Brasil, há uma noção particular de "raça", na qual os "brancos" não são definidos apenas como os descendentes de europeus, mas também como "aqueles mestiços e mulatos claros que podem exibir os símbolos dominantes da europeidade: formação cristã e domínio das letras" (GUIMARÃES, 2005, p. 36).

No entanto, considerando o recorte temporal deste estudo, faz-se necessário, ainda, destacar algumas especificidades das concepções raciais predominantes no Brasil durante as primeiras décadas do século XX.

Hofbauer (2006, p. 217) aponta que a partir da década de 1930 "alguns cientistas começaram a reivindicar o abandono do conceito de raça". No entanto, esse mesmo autor ressalta que somente "depois da Segunda Guerra Mundial, e principalmente na década de 1950, que, no Brasil, o discurso intelectual - hegemônico - do branqueamento sofreu questionamentos sérios" (HOFBAUER, 2006, p. 261). Portanto, durante o 
período de existência da Liga de Futebol José do Patrocínio (1919-1936) ainda predominavam no Brasil as concepções racialistas formuladas no século XIX, segundo as quais havia uma superioridade biológica da raça branca perante a raça negra. Essas percepções acirravam os debates acadêmicos entre defensores e críticos da miscigenação racial, concepção que acabou sendo aceita somente a partir da perspectiva de que isso levaria ao branqueamento da população (ORTIZ, 1985; SCHWARCZ, 1995).

Inserida nesse contexto, a historiografia do futebol brasileiro é constituída não só por uma série de acontecimentos que revelam a existência de uma história de discriminação racial, mas também por lutas e resistência dos futebolistas negros brasileiros. Alguns desses futebolistas viraram referência na historiografia do futebol brasileiro, como é o caso, por exemplo, de Leônidas da Silva, o inventor do lance identificado como "Bicicleta", o Diamante Negro (PRADO, 1994).

Essa memória de resistência, muitas vezes silenciada ou ignorada pela maior parte da historiografia do futebol brasileiro, como veremos neste estudo, remete-se à emergência e à consolidação do futebol brasileiro, nas primeiras décadas do século XX, e estende-se até os dias atuais.

Uma parte significativa dessas memórias de discriminação racial e de resistência ao racismo no futebol brasileiro foi tratada em alguns estudos, como é o caso de "O negro no futebol brasileiro", de Mário Filho (2010), publicado em 1947 e reeditado em 1964. A discussão também aparece em estudos históricos mais atuais, como em Pereira (1998). Ao fazer uma cuidadosa pesquisa histórica sobre o futebol na cidade do Rio de Janeiro, relativa às quatro primeiras décadas do século XX (1902-1938), Pereira ressalta uma série de conflitos político-raciais e futebolísticos que estiveram presentes na gênese dos clubes e na formação das ligas de clubes de futebol da época, no Rio de Janeiro'.

\footnotetext{
1 Pereira (1998, p. 60-61) elencou as exigências que os clubes precisavam cumprir para ingressar na Liga Metropolitana de Foot-Ball, fundada em 1906, no Rio de Janeiro: 1. Pagamento de $50 \$ 000$ (50 mil réis) anuais e 30\$000 de mensalidade; 2. Campo com dimensões regulamentares; 3. Ter seu nome proposto por dois clubes já filiados; 4. Admissão da diretoria. Além disso, alguns clubes ainda definiam em seus estatutos que os jogadores filiados não podiam ser nem ter sido profissionais de qualquer serviço braçal. Em 1907 são alterados os estatutos, transformando-a em Liga Metropolitana de Sports Atléticos e criando restrição à participação de esportistas profissionais e apostas. Em maio do mesmo ano é enviado ofício aos clubes associados comunicando que a diretoria "resolveu por unanimidade de votos que não serão registrados como amadores nesta liga as pessoas de cor" (Ibidem, p. 63), fato que levou o Bangú Athletic Club a se desligar da Liga, para não abandonar os
} 
Todavia, apesar da qualidade de alguns estudos já realizados², persistem certas lacunas. Boa parte dessas lacunas trata-se de memórias de discriminação racial e/ou de resistência ao racismo, produzida por futebolistas negros pouco conhecidos, indivíduos não famosos. Ou, como diz Foucault (2009) "homens infames"3.

Nesse sentido, esta pesquisa centrou-se em analisar e problematizar alguns acontecimentos futebolísticos referentes à Liga José do Patrocínio, uma liga da cidade de Pelotas (RS) constituída, majoritariamente, por futebolistas negros, que foi fundada em 1919 e teve o seu ocaso por volta de 1936. Entretanto, apesar desses dezessete anos de existência, poucos conhecem a Liga José do Patrocínio, um acontecimento futebolístico que permanece ausente da historiografia do futebol gaúcho e brasileiro.

\section{CONSIDERAÇÕES METODOLÓGICAS}

A pesquisa realizada seguiu uma perspectiva metodológica que Michel Foucault (1995; 2000a; 2000b;) denominou de estudos históricos "arque-genealógicos". Essa perspectiva prioriza uma ideia de que, nos estudos históricos, as periodizações temporais ajustam-se às especificidades de cada objeto estudado (FOUCAULT, 1995).

Foucault (2000a) ressalta também que os estudos históricos deveriam centrar-se não nas origens, mas na emergência dos acontecimentos, ou seja, nas forças que fazem com que um determinado objeto ou acontecimento entre em cena e ganhe certa visibilidade. No nosso caso, especificamente, consideramos que a constituição da Liga José do Patrocínio representa a emergência dos clubes de futebol constituídos, predominantemente, por negros e operários, pois, para uma liga existir se faz necessário um grupo de agremiações com características similares.

jogadores negros que faziam parte do seu plantel, passando a integrar a Liga Suburbana de Foot-Ball (Ibidem, p. 64-70).

2 Dentre os trabalhos acadêmicos que tratam da discriminação racial no futebol atual, destacamos: Anjos (2007); Abrahão e Soares (2009; 2011a; 2011b; 2012a; 2012b; 2012c; 2017); Abrahão et. al. (2011); Bandeira e Seffner (2016); Cavalcanti e Caprano (2009); Giglio et. al. (2014); Lise et. al. (2015); Santos et. al. (2010); Souza et. al. (2015).

${ }^{3}$ Em A Vida dos Homens Infames (2009), Foucault utiliza o conceito de infames para tratar de criminosos não famosos, indivíduos desconhecidos cujas vidas costumavam ser contadas em poucas linhas e sobre eles havia escassos registros. 
Ao comentar sobre as singularidades do método histórico de Foucault, Albuquerque Jr. (2000) alerta que tal método não se trata de uma fórmula universal do fazer histórico. Na perspectiva de estudos históricos de Foucault, em cada estudo o pesquisador terá de construir "seu próprio caminho" (ALBUQUERQUE, JR. 2000, p. 29).

O corpus empírico do estudo foi constituído por jornais pelotenses diários e semanais. Fraga (2004, p. 22) lembra que, ao utilizamos os jornais como uma fonte histórica de pesquisa, estamos lidando com "interpretações do acontecido", que trazem consigo as "subjetividades de seus produtores". Ciente dessa condição, utilizamos como referência o trabalho de Loner (1998), que versa sobre os jornais pelotenses diários na república velha, para definirmos os periódicos que a pesquisa iria priorizar. Assim, o estudo teve como suporte empírico os seguintes jornais: "O Correio Mercantil", "Diário Popular", "O Rebate", "O Libertador", "A Opinião Pública" e, principalmente, "A Alvorada", periódico semanal reconhecido como o jornal local mais representativo da classe operária e da população de descendência afrobrasileira, que circulou na cidade de Pelotas entre os anos de 1907 e 1965 (SANTOS, 2003).

Especificamente sobre o uso da fonte jornalística, inspiramo-nos nas indicações metodológicas de Elmir (1995), sobretudo, em dicas operacionais, por exemplo, quando ele lembra que: "[...] a leitura deve ser meticulosa, deve ser demorada, deve ser exaustiva - e muitas vezes é mesmo enfadonha" (ELMIR. 1995, p. 21). Além das fontes escritas, também utilizamos algumas fotografias encontradas nos jornais pesquisados, as quais foram tomadas como representações históricas de uma dada realidade (MAUAD, 1996).

\section{PELOTAS (RS): CIDADE NEGRA}

Pelotas (RS) é uma das cidades de maior população de afrodescendentes do interior do Rio Grande do Sul ${ }^{4}$. Essa configuração está relacionada ao contingente de negros que foram trazidos como escravos para trabalhar nas charqueadas e/ou nos canteiros de obras da área urbana

\footnotetext{
4 Eram 35.049 pretos e 28.245 pardos, enquanto a população total era 328.275, de acordo com - CENSO DEMOGRÁFICO 2010. Rio de Janeiro: IBGE, 2011. Disponível em https://cidades.ibge.gov.br/brasil/rs/pelotas/panorama. Acesso: 18 de maio de 2020.
} 
da cidade no final do século XIX (GUTIERREZ, 1999). Após a abolição, os afrodescendentes radicaram-se na cidade. Em 1890 eles formavam cerca de um terço da população urbana de Pelotas. Durante o século $X X$, os negros sofreram com o preconceito racial e com a exclusão socioeconômica e cultural. $\mathrm{Na}$ luta pela superação desse quadro excludente, os afrodescendentes criaram uma rede de associações, clubes e jornais que os representavam (LONER, 1999).

Inserido nesse contexto citadino de uma forte presença da população afrodescendente, este artigo irá analisar como a Liga de Futebol José do Patrocínio interveio nessa configuração socioeconômica e cultural na cidade de Pelotas. Uma configuração típica da pós-abolição, na qual se predominava o preconceito racial e os mecanismos de constrangimento e preterição da população afrodescendente.

\section{FUTEBOL EM PELOTAS NO COMEÇO DO SÉC. XX}

Uma das primeiras partidas de futebol disputada em Pelotas ocorreu em seis de outubro de 1901, quando o S. C. Rio Grande jogou uma "partida de bola" no Parque Pelotense do Fragata (RIGO, 2004, p. 55-60). Tem-se o registro de que nos anos seguintes ocorreram outras partidas similares a essa. Posteriormente, em 1904, por intermédio de Octávio Mascarenhas, que trouxe da cidade uruguaia de Montevidéu uma bola, fundou-se o Athlético F. B. C., primeiro clube de futebol da cidade de Pelotas do qual se tem registro (ALVES, 1984).

No ano de 1906, proliferam-se nos jornais da cidade notícias sobre a criação de outros clubes. Em $1^{\circ}$ de janeiro de 1906 foi fundado o Club Sportivo, um clube náutico que também se dedicava ao futebol (DIÁRIO POPULAR, 04/01/1906). No dia 10 de janeiro de 1906 foi fundado o Club Sportivo Internacional (DIÁRIO POPULAR, 10/01/1906) e no dia 27 de maio de 1906 o Foot Ball Club, uma dissidência do C. S. Internacional (A OPINIÃO PÚBLICA, 17/06/1907). Mais tarde, em $1^{\circ}$ de junho de 1906, foi fundado o Sport Club União (A OPINIÃO PÚBLICA, 30/05/1907). Ainda em 1906, foram fundados o Sport Club Esperança (A OPINIÃO PÚBLICA, 03/09/1906) e o Club Esportivo 7 de Setembro (A OPINIÃO PÚBLICA, 13/09/1906). 
No ano seguinte (1907), é fundada a Liga Pelotense de Futebol e em 1908 ocorre o primeiro campeonato organizado por essa liga. No entanto, somente participam desse campeonato o Sport Club União, o Foot Ball Club e o Club Sportivo Internacional. No ano seguinte, o campeonato da Liga Pelotense é suspenso e volta a ser disputado somente no ano de 1913, com a participação dos seguintes clubes: Sport Club Pelotas, Sport Club União, Sport Club Rio Branco, Grêmio Sportivo Guarany e Grêmio Sportivo Brasil. Nos primeiros anos de suas atividades, os clubes pertencentes a essa liga eram constituídos majoritariamente por jogadores brancos, pertencentes às "boas famílias da cidade"5 (RIGO, 2004; ALVES, 1984; LONER, 1999).

Todavia, apesar dessa predominância de uma elite branca nos clubes que faziam parte da Liga Pelotense de Futebol nos primeiros anos do século $X X$, rapidamente o futebol pelotense expandiu-se para indivíduos de outras classes sociais. Assim, começou a se proliferar a fundação de agremiações futebolísticas (clubes, times e associações esportivas e culturais) que representavam outros setores da população da cidade, como clubes de operários, clubes de comerciários, clubes de negros e clubes de bairro (LONER, 1999; RIGO, 2004).

Diante de um cenário de crescimento do futebol na cidade, em 1914 é fundada em Pelotas uma segunda Liga de Futebol: a Liga Cassiano do Nascimento. Constam como clubes fundadores dessa liga: Sport Club Benfica, Sport Club Democrata, Colombo Foot Ball Club, Grêmio Pelotense, Sport Club Aliança e Sport Club Internacional (ALVES, 1984, p. 44). Não há muitas informações sobre a Liga Cassiano nos jornais da cidade, principalmente se comparadas às informações referentes à Liga Pelotense de Futebol, mas os indícios sugerem tratar-se de uma espécie de segunda divisão da Liga Pelotense de Futebol, visto que o clube vencedor do campeonato organizado por essa liga, da edição de 1914, o Grêmio Pelotense, no ano seguinte (1915) passou a disputar a Liga Pelotense de Futebol.

Entretanto, apesar disso, foi possível encontrar nos jornais indícios de que havia um tratamento desigual entre os clubes que faziam parte da Liga Pelotense de Futebol e aqueles que pertenciam à Liga Cassiano do

\footnotetext{
${ }^{5}$ O G. S. Brasil, que sempre participou da Liga Pelotense de Futebol e ficou conhecido como o clube dos "negrinhos da estação", começou a incluir jogadores negros em seus planteis, principalmente, a partir do final dos anos 1920 (LONER, 1999; RIGO, 2004).
} 
Nascimento. Um exemplo disso foi o episódio que ocorreu em 1916 com o clube S. C. Democrata. Apesar de ele ter sido o campeão da competição organizada pela Liga Cassiano do Nascimento em 1915, o clube não ascendeu à Liga Pelotense de Futebol em 1916. No ano seguinte, algo similar aconteceu com o Colombo F. C. Por ter sido o Campeão da Liga Cassiano do Nascimento, o clube conquistou o direito de participar da edição de 1917 da Liga Pelotense, mas, em uma atitude de protesto à ascensão do Colombo, o S. C. Pelotas, o G. S. Ideal e o S. C. Rio Branco ameaçam retirar-se da Liga Pelotense, o que fez com que a diretoria da Liga Pelotense voltasse atrás e excluísse o Colombo F. C. do Campeonato de 1917. Em protesto a essa decisão, o Colombo F. C. retirou-se também da Liga Cassiano do Nascimento e passou a disputar a Liga Riograndense de Futebol da cidade de Rio Grande, aproximadamente $70 \mathrm{Km}$ distante de Pelotas (O REBATE, 04/05/1917; ALVES, 1984).

Nessas tensões e conflitos político-futebolísticos envolvendo os clubes da Liga Cassiano do Nascimento e os da Liga Pelotense de Futebol, percebese que os clubes mais elitizados e com maior poder aquisitivo da cidade procuraram apropriar-se e controlar a Liga Pelotense de Futebol, pois, conforme adverte Rigo (2004, p. 82), "quem, como e onde se praticava o futebol fazia parte das intenções da elite da época, que estava atenta para fazer de seu tempo de lazer uma experiência singular de classe". Entretanto, nos anos seguintes, com uma maior inserção das classes populares e da população afrodescendente no universo futebolístico da cidade, os conflitos políticos e raciais no âmbito do futebol irão se diversificar e se fortalecer, potencializando, assim, a emergência de uma terceira liga de futebol em Pelotas.

\section{CLUBES PELOTENSES NEGROS DE FUTEBOL}

Como assinala a historiografia do futebol brasileiro, os conflitos raciais no universo do futebol e no seu entorno não só estiveram como ainda estão presentes em praticamente todo o território nacional. Entretanto, Mascarenhas (1999) observa que o registro de existência de ligas de futebol, especificamente de clubes de futebolistas negros, parece ser uma singularidade do Rio Grande do Sul (RS). Registros históricos apontam que 
existiram, no mínimo, três ligas com essas características em diferentes cidades do estado: em Porto Alegre, a Liga Nacional de Foot-Ball Porto Alegrense, pejorativamente conhecida como Liga da Canela Preta6; em Rio Grande, a Liga Esportiva Rio Branco; e na cidade de Pelotas, a Liga de FootBall José do Patrocínio.

A existência de uma Liga de Futebol pressupõe que mais de um clube esteve diretamente envolvido em sua fundação e manutenção. No caso da Liga José do Patrocínio (objeto deste estudo), os indícios históricos encontrados nos jornais da cidade de Pelotas assinalam que a fundação dessa liga contou com as seguintes agremiações: o Sport Club Juvenil (1908), o Sport Club América do Sul (1911), o Sport Club Universal (1912) e o Grêmio Sportivo Vencedor; e, posteriormente, entre os anos de 1923 e 1935 também disputaram o campeonato organizado por essa Liga o Grêmio Sportivo Democrata e o Grêmio Sportivo Luzitano7 (A TRIBUNA, 24-10-1911; A ALVORADA, 22/06/1919, 05/05/1934, 04/08/1935, 18/08/1935; O REBATE, 20/03/1923; A OPINIÃO PÚBLICA, 02/04/1931; O LIBERTADOR, 23/04/1932).

Entre os clubes fundadores dessa liga, o mais antigo é o S. C. Juvenil, clube composto de operários negros, fundado em 13 de maio de 1908, visto que em 1934, conforme noticiado no periódico A Alvorada, o clube comemorou o seu $26^{\circ}$ aniversário de fundação (A ALVORADA, 05/05/1934).

A primeira informação encontrada nos jornais sobre o S. C. Juvenil é a realização de um match de futebol com o S. C. América do Sul no dia 29 de novembro de 1911 (A TRIBUNA, 28/10/2011). Depois, em 1916 é noticiado que o clube fará um baile na sede do 7 de Setembro (O REBATE, 09/02/1916).

A seguir, apresentamos uma das poucas fotografias encontradas nos jornais da época. Na Figura 1, além do grupo de jogadores de uma composição da equipe de 1922, devidamente fardados, há um grupo de indivíduos com traje social, provavelmente alguns membros da diretoria do S. C. Juvenil. Na fotografia é possível identificar que todos os futebolistas eram negros. Entre os demais indivíduos que aparecem na foto, com traje

\footnotetext{
${ }^{6}$ Santos (2018) destaca que, apesar do protagonismo exercido pela Liga da Canela Preta, nas primeiras décadas do século XX foram criadas na cidade de Porto Alegre outras associações esportivas culturais com características similares a ela, como a Liga de Foot-Ball SulAmericana, fundada em 1911, a Associação dos Amadores de Futebol e a Associação Sportiva de Futebol, ambas fundadas na década de 1920 (SANTOS, 2018).

${ }^{7}$ Não foi possível identificar o ano de fundação do G. S. Vencedor, do G. S. Democrata e do G. S. Luzitano.
} 
social, há tanto indivíduos negros como brancos. O fato de ao menos alguns diretores serem negros assinala que eles não eram apenas jogadores, mas que exerciam um poder estratégico também dentro da diretoria do clube. Esse é um fato que merece destaque, pois nas primeiras décadas do século XX raros são os casos de clubes em que os negros tenham ocupado cargos importantes em suas diretorias ${ }^{8}$, mesmo entre aqueles clubes que foram pioneiros em aceitar os negros como jogadores. Outra singularidade é a boa qualidade da fotografia, que se diferencia da grande maioria das imagens de outros clubes negros da época que eram publicadas nos jornais da cidade de Pelotas.

Figura 1 - Equipe do S. C. Juvenil que disputou a Liga José do Patrocínio, em 1922.

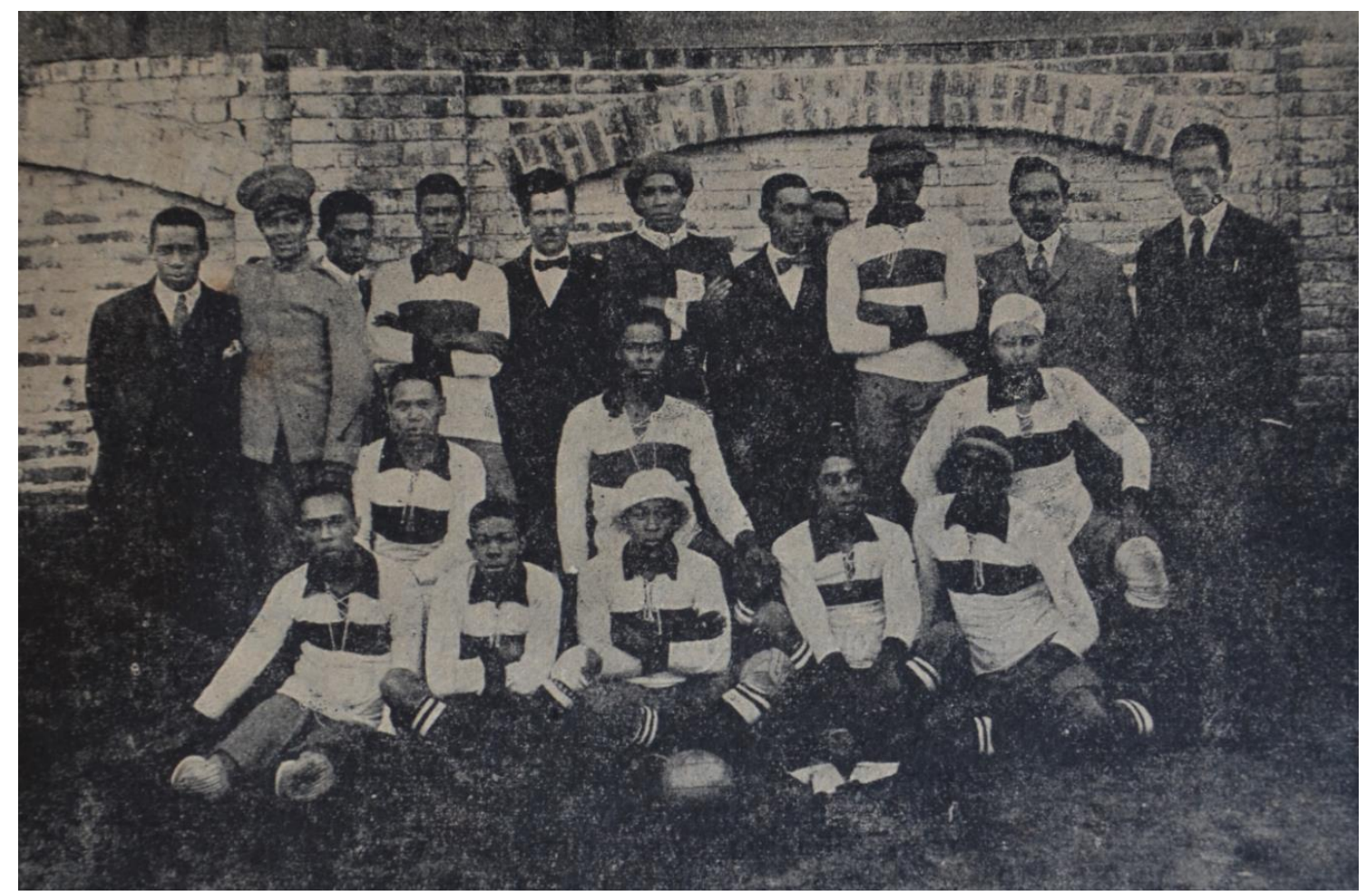

Fonte: A ALVORADA, 15/11/1931.

Sobre as demais agremiações que fizeram parte da Liga José do Patrocínio, poucas foram as informações encontradas nos jornais

\footnotetext{
8 Mesmo no futebol brasileiro atual, apesar do indiscutível lugar de destaque conquistado pelos futebolistas negros, fora de campo a presença de negros como treinadores e dirigentes de clubes ainda é algo a se conquistar, como assinalam algumas reportagens. Disponível em: https://www.torcedores.com/noticias/2019/11/apenas-um-entre-os-40-clubes-das-series-a-e-btem-um-presidente-negro. Acesso: 29 de jan. de 2020; Disponível em: https://observatorioracialfutebol.com.br/me-desculpe-voce-e-preto-tecnicos-reclamam-deracismo/. Acesso: 29 de jan. de 2020.
} 
pesquisados, confirmando que muitas vezes o racismo brasileiro caracterizase, sobretudo, por preterições, por esquecimentos. Todavia, isso não pode consolidar-se como justificativa aceitável para que esses acontecimentos não sejam pesquisados e, no possível, passem a fazer parte da historiografia do futebol. Pois, como adverte Le Goff (1992, p. 109), "falar dos silêncios da historiografia tradicional não basta; penso que é preciso ir mais longe: questionar a documentação histórica sobre as lacunas, interrogar-se sobre os esquecimentos, os hiatos, os espaços em branco da história".

Nessa perspectiva de garimpar pequenos vestígios, encontramos indícios que caracterizavam o S. C. América do Sul como um clube de negros e de operários do Bairro Areal, o qual foi fundado em 1911 (A TRIBUNA, 24/10/1911). No caso do G. S. Vencedor, não conseguimos identificar a data de sua fundação, apenas o registro da sua participação como membro fundador da Liga José do Patrocínio.

Sobre o S. C. Universal, indícios nos levaram a concluir que o clube foi fundado em agosto de 1912, porque em agosto do ano de 1935 o clube festejou seu $23^{\circ}$ aniversário de fundação (A ALVORADA, 04/08/1935, p. 3, e 18/08/1935, p. 2). Do S. C. Universal encontramos, também, publicada em um jornal da cidade no ano de 1931, uma fotografia de uma composição da equipe do clube. Apesar de a fotografia não ter a mesma qualidade da anterior (referente ao S. C. Juvenil), é possível identificar que grande parte dos futebolistas eram afrodescendentes. Trata-se de uma fotografia posada. Nela, os 11 futebolistas (provavelmente os titulares de uma partida ou mesmo de uma competição), aparecem em uma composição que caracteriza a maioria das fotografias do futebol da época: goleiro deitado, cinco jogadores agachados e os outros cinco em pé. 
Figura 2 - S. C. Universal em 1931.

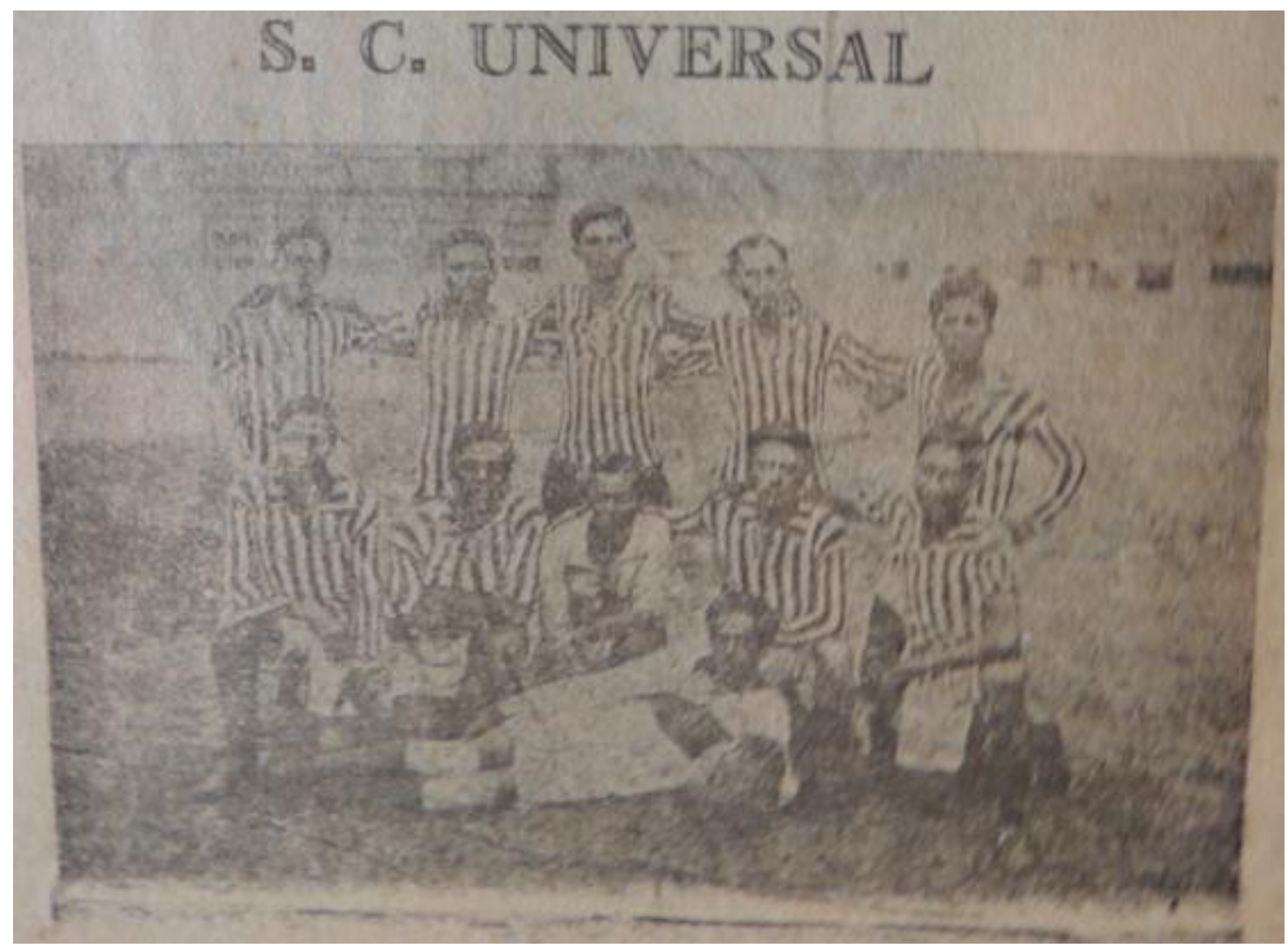

Fonte: A OPINIÃO PÚBLICA, 25/12/1931.

\section{LIGA JOSÉ DO PATROCÍNIO: UM ACONTECIMENTO FUTEBOLÍSTICO}

No ano de 1919, a imprensa negra noticia a possibilidade de fusão dos clubes América do Sul e Juvenil (A ALVORADA, 19/01/1919, p. 2) e cogita a possibilidade de esse novo clube tentar fazer parte da Liga Pelotense de Futebol (A ALVORADA, 02/02/1919, p. 3). No entanto, alguns dias depois, Zé da Várzea ${ }^{9}$ adverte que a ideia estava cada vez mais distante (A ALVORADA, 16/02/1919, p. 1).

Embora o jornal não tenha evidenciado os motivos da não aceitação do clube negro na Liga Pelotense, estudos apontam que, na época, as ligas controladas pelos clubes brancos e mais elitistas costumavam estabelecer critérios e condições que dificultavam as possiblidades de ingresso dos clubes operários e negros.

Ao tratar das condições que os clubes deveriam atender para participar da Liga Metropolitana de Foot-Ball, fundada em 1906, no Rio de

\footnotetext{
9 Pseudônimo de Armando Vargas, futuro membro da primeira diretoria da Liga José do Patrocínio.
} 
Janeiro, Pereira (1998, p. 60-61) salienta que era necessário: 1. Pagamento de $50 \$ 000$ (50 mil réis) anuais e $30 \$ 000$ de mensalidade; 2. Campo com dimensões regulamentares; 3. Nome proposto por dois clubes já filiados; e 4. Admissão da diretoria.

Em 1907 os estatutos dessa liga são alterados, transformando-a em Liga Metropolitana de Sports Atléticos. Nessa (nova) liga, surgem mais normas que visam restringir a possível participação de esportistas profissionais, então, em maio de 1907, a Liga envia um ofício aos clubes associados a ela, comunicando-os de que a diretoria "resolveu por unanimidade de votos que não serão registrados como amadores nesta liga as pessoas de cor" (PEREIRA, 1998, p. 63).

Em Porto Alegre, registros apontam uma postura similar à que ocorria no Rio de Janeiro. Ao acessar os regulamentos da Liga Porto Alegrense de Futebol, Santos (2018) assinala que no ano de 1911 as exigências para os clubes ingressarem na Liga eram: 1. 220\$ (220 réis) para inscrição e 60\$ (60 réis) anuais como mensalidade; 2. Campo com dimensões legais; e 3. Amplas comodidades para os teams visitantes (SANTOS, 2018, pp. 87-91).

Na cidade de Pelotas, em junho de 1919 - quatro meses após a matéria de Zé da Várzea, na qual ele alertava que seria difícil a inclusão de clubes da comunidade negra na Liga Pelotense - é noticiada a fundação da Liga de Futebol José do Patrocínio. Nos jornais da cidade da época, constam como fundadores dessa Liga os seguintes clubes: "América do Sul", "Juvenil", "Universal" e "Vencedor" (A ALVORADA, 22/06/1919, p. 2)10. A coluna Horas Vagas, que abre a edição do A Alvorada, faz uma reflexão sobre o nome da Liga e cita o orgulho frente "a esses que nos depreciam":

Satisfaz-me ver fundada a "Liga de Foot Ball" a qual deram o nome do grande jornalista, cuja memória veneramos com respeito - José do Patrocínio - a quem a nossa raça deve inestimáveis benefícios na extinção da escravidão no Brasil. Sinto-me orgulhoso de ter daqui desta secção despretensiosa, cooperado para a realização desse importante melhoramento, que trará para todos um padrão inextinguível de glórias, que causará inveja a esses que nos depreciam. Aos fundadores da Liga, os meus cumprimentos. (Alvorada, 22/06/1919, p. 1)

\footnotetext{
10 Outros jornais da cidade de Pelotas também noticiaram, de forma bem mais discreta, a criação da Liga: Diário Popular (18/06/1919, p. 3), O Rebate (23/06/1919, p. 2), A Opinião Pública (24/06/1919, p. 2).
} 
Na próxima página da mesma edição, faz-se o seguinte apelo aos leitores: "para que possa levantar o seu ground com a maior brevidade possível. Qualquer donativo pode ser enviado a esta redação" (Alvorada, 22/06/1919, p. 3). Em edições posteriores a convocação é reiterada, e em outras edições do jornal são apresentados alguns detalhes sobre 0 andamento da campanha de arrecadação:

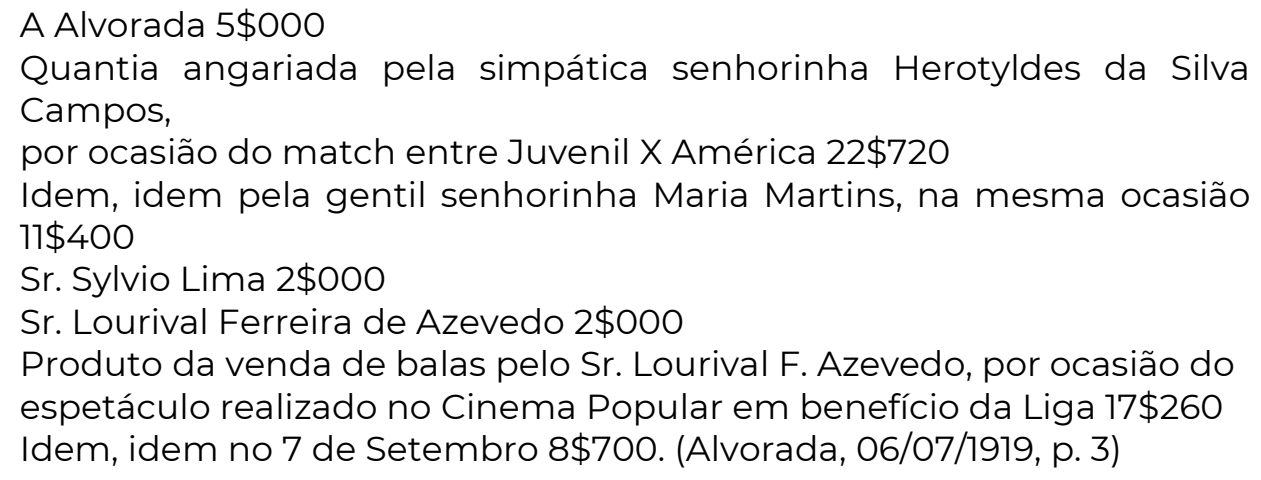

A primeira partida da Liga José do Patrocínio ocorreu em 13 de julho de 1919, às 14 horas, e envolveu o S. C. América do Sul e o S. C. Universal, no campo do primeiro (A ALVORADA, 13/07/1919, p. 6).

A partir da segunda quinzena de julho, os jornais destacam os esforços da Liga para programar jogos amistosos dos clubes pertencentes a ela com clubes de Rio Grande, cidade vizinha, aproximadamente $70 \mathrm{~km}$ distante de Pelotas. Essa iniciativa da Liga é um indício de que havia na cidade de Rio Grande clubes de futebol que possuíam afinidades raciais, políticas e/ou futebolísticas com os clubes integrantes da Liga José do Patrocínio":

Domingo passado, uma comissão da Liga, a convite, foi ao Rio Grande, tratar da organização de jogos intermunicipais, e fazer esforços pela união entre os valentes clubes esportivos daquela cidade, encontrando o melhor acolhimento. Vários esforçados cavalheiros ali residentes, amigos do progresso e das belas iniciativas, hipotecaram a sua solidariedade à Liga José do Patrocínio, prometendo trabalhar com afinco pela união dos mesmos sports. (A ALVORADA, 20/07/1919, p. 2)

Logo as publicações nos jornais começam a evidenciar a dimensão racial da fundação da Liga José do Patrocínio: "É uma causa santa a que está

\footnotetext{
"Mais considerações sobre as marcas operárias e afrodescendentes no futebol rio-grandino em LONER (1999) e Correia et al. (2020).
} 
ativando a Liga, porque não é mais uma questão social, mas sim, uma questão de honra, para combater a prepotência existente contra a raça e contra aqueles que se fazem e vivem pelo trabalho" (A ALVORADA, 20/07/1919, p. 2).

Dois meses depois, o papel militante da Liga contra o preconceito racial é explicitado e reafirmado de maneira mais contundente:

Esta Liga, idealizada, sonhada mesmo, e que hoje aí está, numa marcha acelerada em caminho da construção de sólidos alicerces, há de, em dias vindouros, proporcionar horas agradáveis a todos quantos se hão interessado pela sua prosperidade, ajudando-a a transpor a barreira que certos preconceitos colocaram na estrada, esse abismo que sempre surge em todos os empreendimentos da comunhão social. [...] A nossa luta, a princípio empreendida para minonar (sic) a nossa situação esportiva, é hoje uma questão de honra, não só para nós como para todos os jovens e velhos pertencentes à nossa camada social, que veem e sabem como somos tratados pelos invejosos que por aí andam a pregar a bestialógica separação das raças num "país de mestiçagem". Eis o motivo porque devemos trabalhar todos por um só ideal, para que o mais cedo possível, possamos ver, orgulhosos, tremular na entrada principal do nosso ground, a bandeira triunfal da "Liga de Foot-Ball José do Patrocínio", conquistada após uma série de sacrifícios, batendo-nos denotadamente contra o preconceito racial. (Alvorada, 14/09/1919, p. 1)

\section{FUTEBOL, SOCIABILIDADE E MILITÂNCIA}

Se em 1919 quatro clubes (América do Sul, Juvenil, Universal e Vencedor) fundaram a Liga, a partir de 1923 outras duas agremiações (União Democrata e G. S. Luzitano) passaram a fazer parte da entidade (O REBATE, 05/05/1920; 29/04/1922). Esses seis clubes disputaram as competições organizadas pela Liga até pelo menos 1932 (A OPINIÃO PÚBLICA, O2/O4/1931; O LIBERTADOR, 23/04/1932) ${ }^{12}$.

Sobre os campeonatos organizados pela Liga José do Patrocínio, há registros de que os campeonatos de 1919, 1920, 1922 e 1923 foram vencidos pelo S. C. América do Sul (REBATE, O2/08/1922; ALVES, 1984).

Os campeonatos de 1925 e 1926 foram vencidos pelo S. C. Juvenil, que se tornou tricampeão da Liga, pois havia vencido também a edição de 1921 (ALVES, 1984). Em 1924 a competição foi cancelada por causa da Revolta Paulista de 1924, motivo pelo qual também foi cancelada a competição

\footnotetext{
${ }^{12}$ A não existência das edições da década de 1920 do jornal A Alvorada e do Jornal O Rebate, que parou de ser publicado em 1924, dificultaram a existência de maiores informações sobre a Liga.
} 
organizada pela Liga Pelotense de Futebol e o Campeonato Estadual de Futebol do RS.

Após o campeonato de 1926, há apenas registros referentes aos campeonatos de 1929 e 1931, ambos vencidos novamente pelo S. C. América do Sul (ALVORADA, 06/03/1932, p. 3; ALVORADA, 29/11/1931, p. 2). A final do campeonato de 1931 foi contra o S. C. Juvenil e a partida foi disputada no estádio do Grêmio Esportivo Brasil'13 (ALVORADA, 06/12/1931, p. 3).

Os resultados dos campeonatos apontam que S. C. Juvenil e S. C. América foram os dois clubes que mais conquistaram títulos do campeonato organizado pela Liga José do Patrocínio.

Além da prática do futebol, a Liga José do Patrocínio também desempenhou um papel de destaque na sociabilidade da comunidade negra pelotense. Inúmeros foram os bailes, as festas e as quermesses organizados pelos clubes que pertenciam à Liga ${ }^{14}$. Muitas dessas ações recreativas culturais ocorriam nos salões da Liga Operária e em sociedades recreativas da comunidade negra da cidade, como na sede social do Depois da Chuva ${ }^{15}$.

A organização dessas festividades demandava a participação mais direta de mulheres nos clubes e nas associações recreativas e culturais da época. E, apesar de não haver registro de um futebol de mulheres organizado na época na cidade de Pelotas, elas frequentavam os campos como assistentes e algumas atuavam como torcedoras engajadas. A coluna Pesquei, famosa por fazer intrigas, destaca que, em uma partida entre o S. C. América do Sul e o S. C. Universal, algumas mulheres que estavam assistindo ao jogo gritavam "para o Zéca que matasse o Luiz e o Pery e, quando o Pery caiu, que levou dum pontapé do F., elas disseram: bem feito, que pena que não morreu" (A ALVORADA, 20/07/1919, p. 6).

\footnotetext{
${ }^{13} \mathrm{Na}$ época a nomenclatura era Grêmio Sportivo Brazil.

14 Para mais informações sobre esse aspecto, verificar as seguintes edições: O REBATE (14/10/1922; 16/05/1923; 26/10/23); A ALVORADA (03/04/1932, p. 7; 10/07/1932, p. 2; 14/08/1932, p. 8; 28/10/1933; 25/02/1934; 04/03/1934, p. 3; 08/04/1934; 08/04/1934; 05/05/1934; 27/05/1934; 24/06/1934, p. 3; 14/10/1934; 16/06/1935; 06/10/1935, p. 2).

15 O Depois da Chuva é um clube cultural carnavalesco negro fundado em $1916 \mathrm{em}$ Pelotas (LONER; GILL, 2009), juntamente com outros clubes do mesmo gênero, como o Fica Aí Pra Ir Dizendo (1921), o Chove Não Molha (1919), o Está Tudo Certo (1931) e o Quem Ri De Nós Têm Paixão (1921). Pelo menos dois desses clubes ainda se mantêm em atividade atualmente: Clube Chove Não Molha, disponível em: https://www.facebook.com/pages/Clube-CulturalChove-N\%C3\%A3o-Molha/141972655876026, acesso em: 22 de maio de 2020; e Clube Fica Aí, disponivel em: https://www.facebook.com/pages/Clube-Cultural-FicaA\%C3\%AD/115730328508572, acesso em: 22 de maio de 2020.
} 
Diferente da maior parte das mulheres brancas daquela época, as mulheres negras costumavam ter uma posição relevante nos clubes e nas associações em que participavam (LONER, 1999). Em alguns casos os clubes criaram "diretorias de senhoras", como foi o caso do S. C. Juvenil (O REBATE, 22/09/1923).

Muitos indivíduos atuantes na Liga José do Patrocínio também militavam em outras instâncias contra o racismo, como fez Dário Nunes, que além de ter sido fundador da Liga também foi diretor do Jornal A Alvorada, nas décadas de 1930 e 1940, e membro da diretoria do Clube Fica Aí, no período de 1938 a 1943. Além disso, em 1940, Dário organizou o time de futebol desse clube. Outro exemplo é Armando Vargas, que, além de ter sido secretário da Liga nas duas primeiras diretorias, participou da fundação do Jornal A Alvorada, sendo diretor desse periódico nas décadas de 1930 e de 1940, e membro do Conselho Consultivo da Frente Negra Pelotense (ALVORADA, 22/06/1919; SILVA, 2011).

Ao mapear o associativismo negro em Pelotas no pós-abolição, suas lideranças e a defesa dos direitos dessa população na cidade, Silva (2011) destaca a relevância de alguns desses indivíduos que pertenciam à Liga José do Patrocínio e ressalta, especificamente, a atuação de três lideranças:

Armando Vargas ${ }^{16}$

- Jornal A Alvorada: fundador; diretor nas décadas de 1930 e 1940;

- FNP: membro do conselho consultivo;

- Clube Fica Aí: Associado em 1938-1939.

$[\ldots]$

\section{Dario Nunes}

- Jornal A Alvorada: fundador; diretor nas décadas de 1930 e 1940;

- Liga de Futebol Independente José do Patrocínio: fundador.

- Clube Fica Aí: Membro da diretoria entre 1938-1943; orador em 19391940; organizador do time de futebol do clube, em 1940.

$[\ldots]$

\section{Joaquim Rollo Sobrinho}

- Liga de Futebol Independente José do Patrocínio: fundador.

- Fica Aí: membro do conselho consultivo entre 1938-1939. (SILVA, 2011, p. 8-9)

A atuação das lideranças protagonista na organização da Liga em outras esferas da sociedade civil evidencia a dimensão militante que a caracterizava. Outro exemplo que ilustra esse papel desempenhado pela

\footnotetext{
${ }^{16} 7^{\circ}$ secretário da Liga José do Patrocínio (ALVORADA, 22/06/1919, p. 2).
} 
Liga foi um caso de racismo ocorrido no Teatro Sete de Abril em 1927. O episódio foi ocultado pela impressa local, mas foi denunciado pelo jornal 0 Exemplo de Porto Alegre (O EXEMPLO, 03/07/1927, p. 3; 16/07/1927, p. 1) 17. Em apoio ao Jornal da Capital, a militância negra da cidade pelotense organizou uma "Moção de solidariedade". Nela, destaca-se a assinatura do presidente da Liga José do Patrocínio, de diretores de clubes de futebol e de associações recreativas:

Preconceito de Casta - Moção de solidariedade das Associações e dos homens de cor desta cidade, ao periódico Porto-Alegrense "O Exemplo". Nós abaixo firmados declaramos ao público em geral que estamos em plena solidariedade aos artigos publicados no ' $O$ Exemplo', semanário que se edita em Porto Alegre sobre o caso dos preconceitos de raça, existentes no Teatro 7 de Abril. $O$ Vespertino local 'A Opinião Pública', um dos porta-vozes dessa seleção, entretanto, no dia 12 do corrente, teve o desplante de negar a existência do preconceito de cor, da parte da empresa Xavier \& Santos e da própria sociedade pelotense; e tudo vem demonstrando o contrário. Pelotas, 12 de Julho de 1927. Jose Antonio Ferreira da Silva, p. Liga de Foot Ball José do Patrocínio; Alcides Silveira, p. Sport C. America do Sul; Antonio Falcão, p. Sport C. Juvenil; Anarolino Candiota, p. G. S. Vencedor; Dorval Rozendo Freitas, p. G. S. Lusitano; Raphael Camillo da Rosa, p. Sport C. Monteiro Lopes'18; José Maria Falcão, p. Sport C. Universal; Accacio Caldeira, p. Gremio R. 24 de Junho; Domingos Francisco de Assis, presidente do C. C. Depois da Chuva; A. Barreto, C. C. Fica aí pra ir dizendo, Henrique Cancio de Paula, [.... ${ }^{19}$ Firma Reconhecida. (O LIBERTADOR, 16/07/1927, p. 4)

A atuação sociopolítica de diferentes lideranças que fizeram parte da Liga, em diferentes diretorias, e o posicionamento assumido pela própria Liga em episódios de injúria e de discriminação racial indicam que a Liga e as agremiações que dela fizeram parte exerceram um papel relevante junto

\footnotetext{
17 ○ caso então delatado era o seguinte: "Naquele Teatro trabalha presentemente a 'Companhia Negra de Revistas', pois, justamente nesta ocasião é que figura nos cartazes distribuídos o seguinte: Balcão, na $2^{a}$ ordem, sem distinção de raça ou cor... 5\$000" $(0$ Exemplo, 03/07/1927, p. 3). A edição seguinte do jornal explica melhor: "Informam notícias de Pelotas que, ali, por ocasião dos espetáculos da 'Companhia Negra de Revistas', o proprietário do 'Teatro 7 de Abril', um estrangeiro, que habitualmente só permite a entrada no seu estabelecimento a pessoas de pele branca, consentiu, excepcionalmente, que as pessoas de cor tivessem também ingresso, com a condição porém de se alojarem separadamente, em localidades de categoria inferior" (O Exemplo, 16/07/1927, p. 1).

18 O S. C. Monteiro Lopes, embora não disputasse a Liga, devia se tratar de um clube negro, pois Monteiro Lopes foi um importante deputado negro carioca. Ele aparece no jornal em muitos anos (A ALVORADA, 24/8/1913) e tal hipótese se reforça com a assinatura dessa moção.

19 Seguem-se algumas dezenas de assinaturas.
} 
à comunidade negra na resistência aos discursos e às práticas racistas em Pelotas durante as primeiras décadas do século $X X^{20}$.

Em decorrência da luta contra o racismo em marcha por todo o país e das manifestações de inconformidade e de resistência das entidades e dos grupos negros pelotenses, no final da década de 1920 e no início de 1930, os futebolistas negros começaram, gradualmente, a conseguir adentrar na maior parte das equipes de futebol do país (PEREIRA, 1998) e nas equipes de Pelotas (RIGO, 2004: MACKEDANZ, 2016) que disputavam a Liga Pelotense de Futebol.

Um exemplo que indica uma aproximação ou certa mistura entre os futebolistas e os clubes das distintas ligas da cidade ocorreu no ano de 1931. Nesse ano a Liga José do Patrocínio organiza um torneio no campo do Sport Club Pelotas. Dessa competição, fizeram parte: $2^{\circ}$ time do Sport Club Pelotas, Grêmio Sportivo Ruy Barbosa, Grêmio Sportivo Lealdade, 10 de Junho FootBall Club (composto por jogadores da Liga José do Patrocínio), $2^{\circ}$ time do Grêmio Sportivo Ideal, Sport Club Vaqueiro, Vasco da Gama Foot-Ball Club e Grêmio Sportivo 15 de Novembro (Alvorada, 27/12/1931, p. 3). Além de esse torneio ocorrer no campo do S. C. Pelotas, dele também participaram o $2^{\circ}$ time do S. C. Pelotas e o G. S. Ideal, dois clubes que disputavam a Liga Pelotense de Futebol.

A partir de 1932 diminuem as notícias referentes à Liga nos jornais da cidade. Mesmo assim, foram encontradas informações que apontam que ela seguiu organizando atividades ao menos até o ano de 1935 (A ALVORADA, 31/03/1935, p. 3, p. 5). Depois desse ano, a última notícia encontrada nos jornais da cidade sobre a Liga José do Patrocínio data de 1936, segundo a qual representantes da Liga compareceriam em uma passeata cívica no dia 13 de maio para comemorar a data alusiva ao fim da escravidão, organizada pela Frente Negra Pelotense (A ALVORADA, 05/05/1936, p. 11).

A partir da segunda metade da década de 1930, com a chegada do profissionalismo, aumenta a circulação dos futebolistas entre os clubes das três ligas da cidade (Liga Pelotense de Futebol, Liga Cassiano do Nascimento e Liga José do Patrocínio). Possivelmente esse fato ajudou a enfraquecer o

\footnotetext{
20 O próprio nome da Liga carrega todo um simbolismo, já que José do Patrocínio foi um importante integrante do movimento pela abolição da escravatura (GOMES, 2005). Nas palavras da própria imprensa negra pelotense ele é considerado um "imortal líder negro, da campanha abolicionista" (A ALVORADA, 05/05/1936, p. 11).
} 
campeonato organizado pela Liga José do Patrocínio, tanto que a partir dos anos 40 não se encontrou mais nenhuma informação referente à Liga nos jornais da cidade. Encontrou-se apenas uma ou outra pequena referência a um ou outro clube que fez parte da Liga, mas não à Liga em si. As disputas envolvendo clubes remanescentes da Liga e outros clubes não pertencentes à Liga Pelotense, a partir da década de 1940, passaram a ser nomeadas pelos jornais da cidade como Futebol Menor: "Futebol Menor - América do Sul $3 X$ Liberal 1; Vasco da Gama 3 X F. C. Tecidos 1" (A ALVORADA, 13/03/1948, p. 6).

\section{CONSIDERAÇÕES FINAIS}

Rigo (2004) e Alves (1984) abordaram em seus estudos alguns aspectos da história e das memórias do futebol pelotense. Entretanto, nenhum desses autores dedicou uma maior atenção à dimensão racial do futebol praticado na cidade ou mesmo à Liga José do Patrocínio. Desse modo, ao dedicarmos uma atenção específica à história da Liga José do Patrocínio, um acontecimento futebolístico que foi quase esquecido, ou ignorado, este estudo insere-se em uma perspectiva de contribuir para uma reconfiguração da historiografia e das memórias do futebol pelotense e brasileiro.

Como pudemos observar, as articulações e os entrecruzamentos da Liga José do Patrocínio com outras entidades do campo político e cultural, bem como a atuação de lideranças da Liga em outros espaços do espectro político e sociocultural da cidade, em defesa da comunidade negra pelotense, mostram como o futebol potencializado pela Liga José do Patrocínio esteve longe de servir como um ópio ou como um instrumento de alienação da comunidade negra e operária pelotense. Longe disso, os indícios encontrados apontam que o futebol da Liga produziu efeitos de resistência ao racismo e a outras práticas brancas, elitistas e excludentes que na época vigoravam no Brasil e na cidade de Pelotas.

$\mathrm{Na}$ pesquisa realizada foi possível identificar o ano de fundação da Liga (1919), mas a sua data de término, precisamente, não foi localizada. As informações são vagas, mas alguns indícios apontam que ela teve o seu ocaso por volta do ano de 1936 ou 1937, provavelmente em decorrência da maior inserção dos futebolistas negros e operários nos clubes da Liga 
Pelotense de Futebol, algo que até meados da década de 1920 era bem mais raro de ocorrer. Essa inserção, portanto, parece ter diluído o estratégico papel político-racial-futebolístico que a Liga José do Patrocínio desempenhou enquanto existiu ${ }^{21}$.

No decorrer dos mais de 15 anos em que existiu, a Liga de Futebol José do Patrocínio exerceu um papel de destaque em três áreas: no âmbito desportivo, ao aglutinar clubes negros de futebol e criar um lócus de resistência ao caráter elitista e excludente da Liga Pelotense de Futebol; na esfera social, ao oportunizar diferentes opções de sociabilidade para a população afrodescendente; e, por fim, no campo político, ao fortalecer a militância da comunidade negra pelotense contra o racismo no período pósabolição.

\section{REFERÊNCIAS}

ABRAHÃO, B. O. de L. O "preconceito de marca" e a ambiguidade do "racismo à brasileira" no futebol. Tese de Doutorado, Programa de PósGraduação em Educação Física, Universidade Gama Filho, 2010.

ABRAHÃO, B. O. de L.; PAOLI, P. B.; SOARES, A. J. G. Identidades "Raciais" e Identidades Nacionais: as Representações do Corpo Negro na Construção do "Estilo Brasileiro de Jogar Futebol. Movimento, Porto Alegre, v. 17, n. 2, pp. 195-210, 2011.

ABRAHÃO, B. O. de L.; SOARES, A. J. G. O que o brasileiro não esquece nem a tiro é o chamado frango de Barbosa: questões sobre o racismo no futebol brasileiro. Movimento, v. 15, n. 2, pp. 13-31, 2009.

O corpo negro e os preconceitos impregnados na cultura: uma análise dos estereótipos raciais presentes na sociedade brasileira a partir do futebol. Movimento, Porto Alegre, v. 17, n. 4, p. 265-280, 2011(A).

Os jogos de futebol "preto x branco" e a dramatização da questão racial no brasil. Licere, Belo Horizonte, v. 14, n. 4, 2011(B).

O futebol na construção da identidade nacional: uma análise sobre os jogos "pretos x brancos". Revista Brasileira de Educação Física e Esporte, São Paulo, v. 26, n. 1, pp. 47-61, 2012(A).

\footnotetext{
${ }^{21}$ Entre os clubes da Liga Pelotense, O G. S. Brasil provavelmente foi o clube que mais incorporou futebolistas negros oriundos da Liga José do Patrocínio. Inclusive, no final da década de 1920 e início da década de 1930 o Brasil foi apelidado como o clube dos "Negrinhos da Estação", apelido procedente da aceitação de futebolistas negros e pelo fato de seu estádio, na época, localizar-se ao lado de uma estação ferroviária da cidade (RIGO, 2004).
} 
A imprensa negra e o futebol em São Paulo no início do século $X X$. Revista Brasileira de Educação Física e Esporte, São Paulo, v. 26, n. 1, pp. 6376, 2012(B).

Futebol e lazer: uma análise sobre o "racismo à brasileira" através dos jogos "preto x branco". Licere, Belo Horizonte, v. 15, n. 3, 2012(C).

Futebol, raça e identidade nacional: uma análise do desempenho dos jogadores nos jogos preto $x$ branco. Revista Brasileira de Ciências do Esporte, v. 39, n. 2, pp. 183-190, 2017.

ALBURQUERQUE JR. D. M. Um leque que respira: a questão do objeto em história. In: CASTELO BRANCO, G.; PORTOCARRERO, V. (Org.). Retratos de Foucault. Rio de Janeiro: Nau, 2000. pp. 117-137.

ALVES, E. de M. O futebol em Pelotas. Pelotas: Livraria Mundial, 1984.

ANJOS, J. L. dos. Futebol no sul: história da organização e resistência étnica. Pensar a Prática, Goiania, v. 10, n. 1, pp. 33-50, 2007.

BANDEIRA, G. A.; SEFFNER, F. Aranha, macaco e veado: o legítimo e o não legítimo no zoológico linguístico nos estádios de futebol. Movimento, Porto Alegre, v. 22, n. 3, pp. 985-998, 2016.

CAVALCANTI, E. A.; CAPRARO, A. M. Racismo no futebol sul-americano: o caso Grafite versus Desábato. Motriz, Rio Claro, v. 15, n. 4, pp. 741-748, 2009.

CORREIA, J. M; FREITAS, D. da S.; KNUTH, A. G.; RIGO, L. C. A emergência e a disseminação do futebol na cidade de Rio Grande/RS: uma análise a partir do jornal Echo do Sul (1900-1916). Revista Brasileira de Ciências do Esporte, Porto Alegre, v. 42, n. 1, 2020.

DAMATTA, R. Relativizando: uma introdução à antropologia estrutural. Petrópolis: Vozes, 1981.

Carnavais, malandros e heróis: para uma sociologia do dilema brasileiro. 5 ed. Editora Guanabara: Rio de Janeiro, 1990.

ELMIR, C. P. As armadilhas do jornal: algumas considerações metodológicas de seu uso para a pesquisa histórica. Cadernos de Estudo do PPG em História da UFRGS, Porto Alegre, n. 13, 1995.

FILHO, M. O Negro no Futebol Brasileiro. 5. ed. Rio de Janeiro: Mauad, 2010.

FOUCAULT, M. A vida dos homens infames. In: $O$ que é um autor. 7. ed. Lisboa: Nova veja, 2009.

A arqueologia do saber. Rio de Janeiro, Forense, 1995.

Nietzsche, a genealogia e a história. In: MOTTA, M. B. (Org.). Arqueologia das Ciências e História dos Sistemas de Pensamento/ Michel Foucault. Rio de Janeiro: Forense Universitária, 2000a, pp. 260-281. Ditos \& escritos; II. 
Sobre as maneiras de escrever a história. In: MOTTA, M. B. (Org.). Arqueologia das Ciências e História dos Sistemas de Pensamento/ Michel Foucault. Rio de Janeiro: Forense Universitária, 2000b, pp. 62-77. Ditos \& escritos; II.

FRAGA, G. W. Brancos e Vermelhos: a guerra civil espanhola através das páginas do jornal Correio do Povo (1936-1939). Dissertação (Mestrado em História), UFRGS, Porto Alegre, 2004.

"A derrota do Jeca" na imprensa brasileira: Nacionalismo, Civilização e Futebol na Copa do Mundo de 1950. Tese (Doutorado em História), UFRGS, Porto Alegre, 2009.

GIGLIO, S. S.; TONINI, M. D.; RUBIO, K. 'Do céu ao inferno': a história de Baiano no Boca Juniors e os racismos no futebol. Projeto História (PUCSP), v. 49, pp. 259-292, 2014.

GOMES, F. dos S. Negros e política (1888-1937). Rio de Janeiro: Zahar, 2005.

GUIMARAES, A. S. A. Racismo e Antirracismo no Brasil. 2. ed. São Paulo: Editora 34, 2005.

GUTIERREZ, E. J. B. Barro e sangue: mão-de-obra, arquitetura e urbanismo em Pelotas (1777-1888). Tese (Doutorado em História), PUCRS, Porto Alegre,1999.

LE GOFF, J. História e Memória. Campinas: São Paulo, Ed. Da UNICAMP, 1992.

LISE, R. S. et al. O caso Tinga: análise de (mais) um episódio de racismo no futebol sul-americano. Pensar a Prática, Goiânia, v. 18, n. 4, pp. 821-833, 2015.

LONER, B. A. Classe Operária: Mobilização e Organização em Pelotas: 18881937. Tese (Doutorado em Sociologia), UFRGS, Porto Alegre, v. 1, 1999.

Jornais pelotenses diários na República Velha. Ecos Revista,

Pelotas, v. 2, n. 1, pp. 5-34, 1998.

GILL, L. A. Clubes carnavalescos negros na cidade de Pelotas.

Estudos Ibero-Americanos (PUCRS. Impresso), v. 35, pp. 145-162, 2009.

GILL, L. A.; MAGALHÃES, M. O. (Orgs.). Dicionário de História de Pelotas. Pelotas, Ed. Da UFPel, 2010.

MACKEDANZ, C. F. Racismo "nas quatro linhas": os negros e as ligas de futebol em Pelotas (1901-1930). Dissertação (Mestrado em História), Instituto de Ciências Humanas, Universidade Federal de Pelotas, 2016.

MASCARENHAS, G. O futebol da Canela Preta: o negro e a modernidade em Porto Alegre (RS). Anos 90 (UFRGS), Porto Alegre, v. 11, pp. 144-161, 1999.

MAUAD, A. M. Através da imagem: fotografia e história, interfaces. Tempo, Rio de Janeiro, v. 1, n. 2, 1996, pp. 73-98. 
ORTIZ, R. "Memória coletiva e sincretismo: as teorias raciais do séc. XIX". In: Cultura brasileira \& identidade nacional. São Paulo: Editora brasiliense, 1985.

PEREIRA, L. A. de M. Footballmania: uma história social do futebol no Rio de Janeiro (1902-1938). Tese (doutorado) - Universidade Estadual de Campinas, Instituto de Filosofia e Ciências Humanas. Campinas, 1998.

PRADO, D. A. Recordações de Leônidas (Da Silva): o inventor da bicicleta voadora. Revista Dossiê Futebol, USP, São Paulo, 1994. pp. 27-29.

RIGO, L. C. Memórias de um Futebol de Fronteira. Pelotas: Editora Universitária UFPel, 2004.

SANTOS, J. A. dos. Raiou a Alvorada: intelectuais negros e imprensa, Pelotas (1907-1957). Pelotas: Editora Universitária UFPel, 2003.

Liga da Canela Preta: a história do negro no futebol. Porto Alegre: Diadorim Editora, 2018.

SANTOS, N.; CAPRARO, A.; LISE, R. Racismo e a derrota que não foi esquecida: uma análise dos discursos de Mário Filho e da imprensa escrita acerca da final da Copa do Mundo de 1950. Movimento, Porto Alegre, v. 16, n. 4, pp. 191208, 2010.

SCHWARCZ, L. K. M. "Nomeando as diferenças: a construção da ideia de raça no Brasil", in: VILLAS BOAS, G.; GONÇALVES, M. A. (org.). O Brasil da virada do século: o debate dos cientistas sociais. Rio de Janeiro: Relume Dumará, 1995.

SILVA, F. O. da. Associativismo negro em Pelotas no pós-abolição: membros dos clubes sociais negros, articulistas do A Alvorada e militantes da Frente Negra Pelotense (1933-1937). In: V Encontro de Escravidão e Liberdade no Brasil Meridional, Porto Alegre, 2011.

SOUZA, M. T. O. S.et al. Injúria racial no futebol brasileiro: uma análise sóciohistórica de alguns casos (não tão) esporádicos ocorridos nos últimos anos. Motrivivência, Florianópolis, v. 27, n. 46, pp. 230-240, 2015.

TOLEDO, L. H. de. Lógicas no futebol: dimensões simbólicas de um esporte nacional. Tese (Doutorado em Antropologia Social), USP, São Paulo, 2000.

\section{Edições do Jornal A Alvorada}

08/12/1912; 24/08/1913; 31/08/1913; 19/01/1919; 26/01/1919; 02/02/1919; 09/02/1919; 16/02/1919; 11/05/1919; 18/05/1919; 22/06/1919; 29/06/1919; 06/07/1919; 13/07/1919; 20/07/1919; 27/07/1919; 10/08/1919; 14/09/1919; 12/10/1919; 19/10/1919; 02/11/1919; 16/11/1919; 15/11/1931; 22/11/1931; 29/11/1931; 06/12/1931; 27/12/1931; 06/03/1932; 03/04/1932; 10/07/1932; 14/08/1932; 28/10/1933; 25/02/1934; 04/03/1934; 18/03/1934; 08/04/1934; 05/05/1934; 27/05/1934; 10/06/1934; 14/10/1934; 06/01/1935; 24/03/1935; 31/03/1935; 05/05/1935; 12/05/1935; 26/05/1935; 
02/06/1935; 16/06/1935; 04/08/1935; 18/08/1935; 06/10/1935; 03/11/1935; 01/12/1935; 22/12/1935; 12/04/1936; 05/05/1936; 28/02/1948; 13/03/1948; 22/10/1955.

\section{Edições do Jornal A Tribuna}

01/04/1911; 05/05/1911; 24/10/1911; 28/10/1911.

\section{Edições do Jornal Correio Mercantil}

20/07/1910; 26/08/1914; 03/09/1929; 11/10/1929.

\section{Edições do Jornal Diário Popular}

05/10/1901; 04/01/1906; 10/01/1906; 07/03/1913; 18/06/1919; 27/04/1927; 14/03/1935; 15/01/1937; 21/01/1939.

\section{Edições do Jornal O Libertador}

16/01/1926; 07/05/1926; 10/05/1926; 05/06/1926; 07/06/1926; 28/08/1926; 07/05/1927; 16/07/1927; 22/09/1927; 23/04/1932; 27/05/1932; 10/06/1932; 07/03/1935.

\section{Edições do Jornal O Rebate}

02/02/1915; 06/03/1915; 09/03/1915; 26/03/1915; 16/04/1915; 18/09/1915; 23/10/1915; 30/10/1915; 08/11/1915; 15/01/1916; 05/02/1916; 09/02/1916; 07/06/1916; 24/06/1916; 23/10/1916; $\quad 04 / 05 / 1917 ; \quad 23 / 06 / 1919 ; \quad 25 / 09 / 1919 ; \quad 09 / 01 / 1920 ; \quad 05 / 05 / 1920 ;$ 29/05/1920; 22/06/1920; 07/07/1920; 05/07/1920; 06/09/1920; 08/10/1920; 02/04/1921; 02/07/1921; 13/08/1921; 16/09/1921; 21/09/1921; 24/03/1922; 29/04/1922; 15/06/1922; 17/06/1922; 02/08/1922; 14/10/1922; 06/11/1922; 07/11/1922; 22/12/1922; 22/09/1923; 20/03/1923; 06/04/1923; 16/05/1923; 22/09/1923; 26/10/1923.

\section{Edições do Jornal Opinião Pública}

19/07/1906; 03/09/1906; 13/09/1906; 17/06/1907; 23/05/1907; 30/05/1907; 25/05/1908; 16/08/1912; 05/05/1913; 29/04/1916; 24/06/1919; 27/10/1927; 15/10/1928; 15/01/1929; 02/10/1929; 06/05/1930; 02/04/1931; 25/12/1931; 08/07/1932; 30/07/1932; 06/08/1932; 22/05/1933; 24/06/1933; 01/03/1934; 26/01/1937; 27/03/1937; 17/04/1937. 